\title{
Prevalence, genotype distribution, and risk factors for hepatitis $C$ infection among HIV-infected individuals in Slovenia: a 1986-2013 update
}

\author{
Mateja Škamperle ${ }^{1}$, Katja Seme ${ }^{1}$, Maja M. Lunar ${ }^{1}$, Polona J. Maver ${ }^{1}$, Janez Tomažič̌ ${ }^{2}$, Tomaž D. Vovko², Blaž Pečavar², \\ Mojca Matičič ${ }^{2}$, Mario Poljak ${ }^{1 凶}$
}

\begin{abstract}
Introduction: Since the introduction of highly active antiretroviral therapy, chronic hepatitis C has become one of the leading causes of non-AIDS-related morbidity and mortality in patients with HIV infection. Two previous Slovenian nationwide studies published in 2002 and 2009 showed a very low prevalence of hepatitis C virus (HCV) infection among Slovenian HIV-infected individuals $(14.5 \%$ and $10.7 \%$, respectively).

Methods and results: The presence of HCV infection was tested in 579/639 (90.6\%) patients that were confirmed as HIV-positive in Slovenia by the end of 2013. Among them, 7.6\% (44/579) of HIV-infected individuals were anti-HCV-positive, and 33/44 (75\%) anti-HCV-positive patients were also HCV RNA-positive. HCV genotype 1 was most prevalent among HIV-infected patients (68\%), followed by genotype $3(20 \%)$, genotype $4(8 \%)$, and genotype $2(4 \%)$. Anti-HCV positivity was significantly higher in those that acquired HIV by the parenteral route ( $91.8 \%$ ) than in those that acquired HIV by the sexual route $(2.8 \%)$.

Discussion: Slovenia remains among the countries with the lowest prevalence of HCV infection in HIV-infected individuals. Because the burden of HIV among men who have sex with men in Slovenia is disproportionately high and increasing rapidly, the current favorable situation could change quickly and should be therefore monitored regularly.
\end{abstract}

Received: 24 April 2014 | Returned for modification: 8 May 2014 | Accepted: 30 May 2014

\section{Introduction}

Due to the use of highly active antiretroviral therapy (HAART), which has prolonged the survival of HIV-infected individuals (1), and significant overlap in the transmission pathways of hepatitis $\mathrm{C}$ virus (HCV) and HIV, chronic hepatitis $\mathrm{C}$ has become one of the leading causes of non-AIDS-related morbidity and mortality in patients with HIV infection (2). Coinfection with HCV occurs in $25 \%$ of HIV-infected individuals, although rates vary widely in different patient populations and are the highest among intravenous drug users (IVDU) and men who have sex with men (MSM) (3-5).

Slovenia is a small central European country with a relatively low prevalence but increasing incidence of HIV infection (6). The burden of HIV among MSM in Slovenia is disproportionately high and increasing quickly, whereas it is very low among IVDU (7). In our previous nationwide studies published in 2002 and 2009, we found a very low prevalence of HCV infection among Slovenian HIV-infected individuals (14.5\% and $10.7 \%$, respectively) $(8,9)$. Because several developed countries have recently faced a dramatic increase in the incidence of acute hepatitis C among HIVinfected MSM (10-12), here we have updated the HCV infection prevalence data in Slovenian HIV-infected individuals.

\section{Methods}

For the purpose of this study, data collected for the most recent published study on the topic (9) were updated with those obtained from 230 Slovenian individuals that were newly diagnosed as HIVpositive between 1 January 2009 and 31 December 2013. Overall, 579 of 639 (90.6\%) patients that were confirmed as HIV-positive by the end of 2013 were tested for the presence of HCV infection.
The presence of anti-HCV was determined using the Ortho HCV Assay (Ortho Diagnostic Systems). Anti-HCV reactive specimens were confirmed by the Inno-Lia HCV Ab III Update Assay (Innogenetics, Zwijndrecht, Belgium). HCV RNA was detected using several generations of commercial HCV RNA viral load assays.

\section{Results}

Among 579 individuals included in the study, 505 (87.2\%) were men and 74 (12.8\%) women, and mean age at the time of HIV diagnosis was 37.4 years (range $0-76$ years). The sexual transmission route was predominant $(483.5 / 579,83.5 \%)$, followed by the parenteral HIV transmission route (24.5/579, 4.2\%), motherto-child transmission $(6 / 579,1.0 \%)$, and transmission by human bite $(1 / 579,0.2 \%)(13)$. The route of transmission was unknown for $64 / 579$ (11.1\%) HIV-infected individuals. MSM accounted for $62.9 \%$ of all HIV-infected individuals included in the study.

The presence of anti-HCV antibodies was detected in $7.6 \%$ (44/579) HIV-infected individuals. Thirty-three out of 44 (75\%) seropositive patients were also HCV RNA-positive. HCV RNA was not detected in any of the 535 anti-HCV-negative HIV-infected individuals. HCV genotype 1 was most prevalent among HIV-infected patients $(68 \%)$, followed by genotype $3(20 \%)$, genotype 4 (8\%), and genotype $2(4 \%)$.

Anti-HCV positivity was significantly higher in those that acquired HIV by the parenteral route $(91.8 \%)$ than in those that acquired HIV by the sexual route (2.8\%).

\section{Discussion}

In Slovenia, screening for HCV infection has been the standard of

${ }^{1}$ Institute of Microbiology and Immunology, Faculty of Medicine, University of Ljubljana, Slovenia. ${ }^{2}$ Clinic for Infectious Diseases and Febrile IIlnesses, University Medical Centre Ljubljana, Ljubljana, Slovenia. $\bowtie$ Corresponding author: mario.poljak@mf.uni-lj.si 
medical care in management of HIV-infected individuals since 2001. The study performed in 2002 demonstrated a low prevalence $(14.5 \%)$ of HCV infection among Slovenian HIV-infected individuals (8). In a follow-up study performed on $87 \%$ of the entire population of Slovenian HIV-infected individuals identified by the end of 2008, the prevalence of HCV infection decreased to $10.7 \%$ (9). In the present study, which included $90.6 \%$ of the entire population of Slovenian HIV-infected individuals identified by the end of 2013, a further decrease in the prevalence of HCV infection was observed and reached only $7.6 \%$. The predominance of HCV genotype 1 among HIV-infected individuals followed by HCV genotype 3 remained unchanged and is in agreement with the HCV genotype distribution in the general population of HCVpositive individuals in Slovenia (14). As noticed in our previous studies, the HCV infection in those that acquired HIV by the parenteral route predominated over individuals that acquired HIV by the sexual route. There are probably two main reasons for the unusual relatively low prevalence of HCV infection among Slovenian HIV-infected individuals. Namely, the IVDU population in Slovenia has so far largely been spared from HIV infection and it also

\section{References}

1. Palella FJ Jr, Delaney KM, Moorman AC, Loveless MO, Fuhrer J, Satten GA, et al. Declining morbidity and mortality among patients with advanced human immunodeficiency virus infection. HIV Outpatient Study Investigators. N Engl J Med. 1998;338:853-60.

2. Weber R, Sabin CA, Friis-Møller N, Reiss P, El-Sadr WM, Kirk O, et al. Liver-related deaths in persons infected with the human immunodeficiency virus: the $D: A: D$ study. Arch Intern Med. 2006;166:1632-41.

3. Puoti M, Moioli MC, Travi G, Rossotti R. The burden of liver disease in human immunodeficiency virus-infected patients. Semin Liver Dis. 2012;32:103-13.

4. Soriano V, Puoti M, Sulkowski M, Cargnel A, Benhamou Y, Peters M, et al. Care of patients coinfected with HIV and hepatitis C virus: 2007 updated recommendations from the HCV-HIV International Panel. AIDS. 2007;21:1073-89.

5. Soriano V, Vispo E, Fernandez-Montero JV, Labarga P, Barreiro P. Update on HIV/ HCV coinfection. Curr HIV/AIDS Rep. 2013;10:226-34.

6. Klavs I, Kustec T, Kastelic Z. Okužba s HIV v Sloveniji, letno poročilo 2012. [HIV infection in Slovenia, annual report 2012] [Internet]. Ljubljana: National Institute of Public Health. 2013 - [cited 2014 May 29]. Available from: http://www.ivz.si/hiv_spo/.

7. Klavs I, Bergant N, Kastelic Z, Lamut A, Kustec T. Disproportionate and increasing burden of HIV infection among men who have sex with men in Slovenia: surveillance data for 1999-2008. Euro Surveill. 2009;14.pii:19419.

8. Seme K, Poljak M, Begovac J, Vince A, Tomažič J, Vidmar L, et al. Low prevalence of hepatitis $C$ virus infection among human immunodeficiency virus type 1-infected individuals from Slovenia and Croatia. Acta Virol. 2002;46:91-4. seems that the MSM population in Slovenia has so far largely been spared from HCV infection. However, the situation may change in the near future because we recently detected a few acute hepatitis $\mathrm{C}$ cases among HIV-infected MSMs.

\section{Conclusion}

Slovenia remains among the countries with the lowest prevalence of HCV infection among HIV-infected individuals. Because the burden of HIV among MSMs in Slovenia is disproportionately high and increasing rapidly, the current favorable situation could quickly change and should therefore be monitored regularly.

Results from this study were partially presented at the 7 th Romanian National HIV/AIDS Congress and 2nd Central European HIV Forum in Sibiu Romania May 29-30, 2014, Sibiu, Romania. Published abstract: Seme K, et al. Low prevalence of hepatitis $\mathrm{C}$ infection among HIV-infected individuals in Slovenia: a nationwide study, 1985-2013. BMC Infectious Diseases 2014; 14 (Suppl 4): 015.
9. Seme K, Lunar MM, Tomažič J, Vidmar L, Karner P, Matičič M, et al. Low prevalence of hepatitis B and C infections among HIV-infected individuals in Slovenia: a nation-wide study, 1986-2008. Acta Dermatovenerol Alp Panonica Adriat. 2009;18:153-6.

10. Urbanus AT, van de Laar TJ, Stolte IG, Schinkel J, Heijman T, Coutinho RA, et al. Hepatitis C virus infections among HIV-infected men who have sex with men: an expanding epidemic. AIDS. 2009;23:F1-7.

11. Hasse B, Ledergerber B, Hirschel B, Vernazza P, Glass TR, Jeannin A, et al. Frequency and determinants of unprotected sex among HIV-infected persons: the Swiss HIV cohort study. Clin Infect Dis. 2010;51:1314-22.

12. Finlayson TJ, Le B, Smith A, Bowles K, Cribbin M, Miles I, et al. HIV risk, prevention, and testing behaviours among men who have sex with men - National HIV Behavioral Surveillance System, 21 U.S. cities, United States, 2008. MMWR Surveill Summ. 2011;60:1-34.

13. Vidmar L, Poljak M, Tomažič J, Seme K, Klavs I. Transmission of HIV-1 by human bite. Lancet. 1996;347:1762-3.

14. Seme K, Vrhovac M, Močilnik T, Matičič M, Lešničar G, Baklan Z, et al. Hepatitis C virus genotypes in 1,504 patients in Slovenia, 1993-2007. J Med Virol. 2009;81:634-9. 